\title{
Production and productivity of 1,3-propanediol from glycerol by Klebsiella pneumoniae GLC29
}

\author{
Gervásio Paulo da Silva ${ }^{\mathrm{a}, *}$, Cristian J. Bolner de Lima $^{\mathrm{b}}$, Jonas Contiero ${ }^{\mathrm{b}}$ \\ a Microorganism Biotechnology Laboratory, Education Department, Bahia State University (UNEB), BR 407, Km 127, CEP 48970-000, Senhor do Bonfim, BA, \\ Brazil \\ ${ }^{\mathrm{b}}$ Industrial Microbiology Laboratory, Biochemistry and Microbiology Department, Biological Sciences Institute, São Paulo State University (UNESP), Av 24A, \\ 1515, Bela Vista, CEP 13506-900, Rio Claro, SP, Brazil
}

\section{A R T I C L E I N F O}

\section{Article history:}

Received 27 February 2014

Received in revised form 11 May 2014

Accepted 17 May 2014

Available online 30 June 2014

\section{Keywords:}

Biodiesel

Glycerol

Fermentation

1,3-Propanediol

Klebsiella pneumoniae GLC29

\begin{abstract}
A B S T R A C T
Interest in the development of the bioproduction of 1,3-propanediol, an important chemical intermediate with various industrial applications, has increased in recent years. Klebsiella pneumoniae is one of the most studied and efficient bacteria for 1,3-propanediol production from glycerol. A new isolate of $K$. pneumoniae was investigated using response surface methodology by central composite design for the production of 1,3-propanediol using glycerol. The effects of $\mathrm{pH}$, temperature, stirrer speed, and glycerol concentration on the production and productivity of 1,3-propanediol were examined. Considering both production and productivity, the best conditions for glycerol conversion in 1,3-propanediol are: a pH range of 6.9-7.1, a temperature between 33 and $38.5^{\circ} \mathrm{C}$, a stirrer speed of $110-180 \mathrm{rpm}$, and a glycerol concentration of 39-49 $\mathrm{g} \mathrm{l}^{-1}$. Batch fermentation carried out at a $\mathrm{pH}$ of 7.0 , a temperature of $35^{\circ} \mathrm{C}$, a stirrer speed of $150 \mathrm{rpm}$, and a glycerol concentration of $40 \mathrm{~g} \mathrm{l}^{-1}$ produced $20.4 \mathrm{~g} \mathrm{1,3-propanediol} \mathrm{l}^{-1}$, with a maximum volumetric productivity of $2.92 \mathrm{~g} \mathrm{l}^{-1} \mathrm{~h}^{-1}$ and a yield of $0.51 \mathrm{~g} \mathrm{~g}^{-1}$. The main byproducts were acetic acid (approximately $7.0 \mathrm{~g} \mathrm{l}^{-1}$ ) and formate (approximately $3.7 \mathrm{~g} \mathrm{l}^{-1}$ ). The newly isolated K. pneumoniae GLC29 showed potential for the conversion of glycerol into 1,3-propanediol, with high production and productivity.
\end{abstract}

(c) 2014 Elsevier B.V. All rights reserved.

\section{Introduction}

In recent years, many countries have adopted biofuels, such as biodiesel, an alternative diesel fuel produced from renewable sources. Their increased use is related to environmental pollution caused by the emission of greenhouse gases into the atmosphere mainly through the burning of fossil fuels. Fossil oil is a non-renewable resource, thus leading to price instability in the international market. Biodiesel is a mono-alkyl ester of long chain fatty acids produced from vegetable oils and animal fats. A transesterification reaction between the oil and an alcohol in the presence of a catalyst produces esters (biodiesel) and about $10 \%$ glycerol $(\mathrm{w} / \mathrm{w})$ as a byproduct [1]. Glycerol, a substance recognized as safe for human and animal health, is a chemical with widespread uses in several industrial sectors, like food, cosmetics and pharmaceutical industries, but the increasing biodiesel production worldwide is responsible for the generation of a glycerol surplus in the market. Crude glycerol from biodiesel refineries consists of glycerol, water,

\footnotetext{
* Corresponding author. Tel.: +55 7435418929.

E-mail addresses: gpsilva@uneb.br, gpaulosilva@yahoo.com.br (G.P. da Silva).
}

salts such as potassium, and residual alcohol [2,3]. Glycerol must be highly purified to be used in products such as drugs and food, and the high cost of purification makes this process impractical for the glycerol derived from biodiesel industries [4].

This glycerol surplus is an environmental problem for biorefineries since its disposal and/or storage generates economic costs, raising the final biodiesel price. Therefore, the search for new glycerol applications is one objective of researchers and industries. Possibilities for new glycerol utilization by chemicals [5] or industrial microbiology [1] have been reviewed. Among possible new applications in the chemical industry is the use of glycerol as a raw material for the production of various chemicals, including mesoxalic acid, 1,3-dicloropropanol, glyceryl ethers, glycerol carbonate, glyceryl esters, hydroxypyruvic acid, and polyglycerol [5]. Biotechnologically, glycerol can be converted by microorganisms in a number of valuable chemicals such as 1,3-propanediol, dihydroxyacetone, succinic, propionic, and citric acids, ethanol, pigments, polyhydroxyalkanoates, biosurfactants, 2,3-butanediol, amino acids, glyceric acids, D-xylulose, hydrogen, 3-hydroxypropionaldehyde, and fatty acids [1,6-16]. Microbial bioconversion of glycerol has a number of advantages over chemical synthesis, including a greater selectivity on the final products, 
efficiency, and a shorter reaction time. In general, chemical synthesis requires several intermediate steps before reaching the final product, specific catalysts, and extreme and well controlled conditions such as high temperatures and high pressures [5,9], which favor the biotechnological route of glycerol bioconversion [17].

One of the main products obtained through microbial bioconversion of glycerol is 1,3-propanediol (1,3-PDO), a polyol with applications in the cosmetics, food, lubricant, and pharmaceutical industries [18-21]. The development of polypropylene terephthalate (PPT), a thermoplastic with superior physicochemical properties to those of polyethylene terephthalate (PET), used in the production of fabrics, carpets, and engineered plastics has created a new demand for 1,3-propanediol. Interest in the commercial production of 1,3-PDO through either chemical synthesis or microbial conversion of glycerol has increased in recent years. Chemically, 1,3-PDO is produced through two different routes. One of them uses acrolein (2-propenal) as a raw material, which is hydrated to 3-hydroxypropionic acid, which is then hydrogenated in the presence of a catalyst to 1,3-PDO. Another route involves the hydroformylation of ethylene oxide with $\mathrm{CO}$ and $\mathrm{H}$ under high pressure in the presence of a catalyst and a solvent [18]. This reaction produces a dioxane that is hydrogenated to 1,3-PDO. These methods are expensive, create pollutants, [22] and are dependent on crude oil.

Bioconversion of glycerol into 1,3-propanediol has been demonstrated only in bacteria, such as Citrobacter freundii, Klebsiella pneumoniae, Clostridium pasteurianum, Clostridium butyricum, and Enterobacter agglomerans $[1,18,23,24]$. One of the most studied and efficient bacteria for 1,3-propanediol production is $K$. pneumoniae $[18,24]$. A number works have focused on improving the production and productivity of 1,3-propanediol using glycerol. Yang et al. [25], in fed-batch fermentation at a $\mathrm{pH}$ of 7.0, a temperature of $37^{\circ} \mathrm{C}$, and microaerobiosis, using mutants of $K$. oxytoca deficient in lactate formation and sucrose as a co-substrate, obtained $83.56 \mathrm{~g}$ $1,3-\mathrm{PDOl}^{-1}$, with a yield of $0.62 \mathrm{~mol} \mathrm{~mol}^{-1}$, and a productivity of $1.61 \mathrm{~g} \mathrm{l}^{-1} \mathrm{~h}^{-1}$, with $60.11 \mathrm{gl}^{-1}$ of 2,3-butanediol (2,3-BDO) produced in parallel with 1,3-PDO. Seo et al. [26] obtained mutants deficient in the oxidative pathway, however, the production of 1,3PDO was not improved, probably due to a redox imbalance. Zhu et al. [27] cloned the $y q h \mathrm{D}$ gene encoding 1,3-propanediol oxidoreductase isoenzyme (PDORI) from Escherichia coli in K. pneumoniae. The overexpression of PDORI led to a higher 1,3-PDO production, reaching $67.6 \mathrm{~g} \mathrm{l}^{-1}$. In addition, the concentration of the toxic intermediate 3-hydroxypropionaldehyde was reduced by $22.4 \%$ when compared to the original strain. Huang et al. [15] examined the effects of an over-expressed aldehyde dehydrogenase gene on the simultaneous production of 3-hydroxypropionic acid and 1,3-PDO by K. pneumoniae, obtaining $24.4 \mathrm{gl}^{-1}$ and $49.3 \mathrm{~g} \mathrm{l}^{-1}$, respectively. A high production of 1,3-PDO using co-substrates is recorded by $\mathrm{Oh}$ et al. [28] using K. pneumoniae mutant deficient in carbon catabolite repression. Under optimized conditions, the concentration of 1,3PDO from glycerol was $81.2 \mathrm{~g} \mathrm{l}^{-1}$ using molasses as a co-substrate.

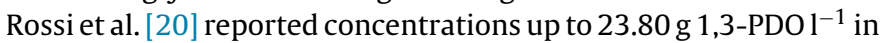
batch fermentations under controlled $\mathrm{pH}$, while in fed-batch cultivations the 1,3-PDO production was $36.86 \mathrm{~g} \mathrm{l}^{-1}$ using a new strain of K. pneumoniae. Sattayasamitsathit et al. [29] applied a statistical optimization for the simultaneous production of 1,3-PDO and 2,3-BDO using crude glycerol by a new $K$. pneumoniae isolate. They

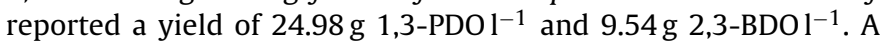
high production of 1,3-PDO by a D-lactate deficient mutant of $K$. pneumoniae was reported by Xu et al. [30], obtaining $102.06 \mathrm{~g}$ 1,3$\mathrm{PDOl}^{-1}$ from aerobic fed-batch fermentation. The same approach was tested by Durgapal et al. [31], which was used to construct a K. pneumoniae mutant for lactate formation. In glycerol fed-batch

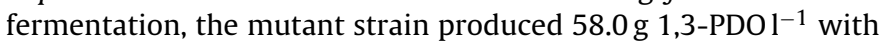
a yield of $0.35 \mathrm{~g} \mathrm{~g}^{-1}$ and 2,3-BDO as the main byproduct $\left(26.6 \mathrm{gl}^{-1}\right)$.
In this work, response surface methodology was used to determine the interaction effect of four independent variables $(\mathrm{pH}$, temperature, stirrer speed, and glycerol concentration) on 1,3propanediol production and productivity by a new $K$. pneumoniae isolate.

\section{Materials and methods}

\subsection{Isolation and identification of microorganisms}

For the isolation of microorganisms that use glycerol as their only carbon and energy source, Erlenmeyer flasks containing an enrichment minimal medium ( $\mathrm{g} \mathrm{l}^{-1}$ of deionized water: $\mathrm{NH}_{4} \mathrm{H}_{2} \mathrm{PO}_{4}$ $1.0, \mathrm{~K}_{2} \mathrm{HPO}_{4} 1.0, \mathrm{MgSO}_{4} 0.2, \mathrm{NaCl} 5.0$, glycerol 20) were directly inoculated with different natural samples (soil, decaying plant, leaves, mosses, etc.) and incubated at $30^{\circ} \mathrm{C}$ and $100 \mathrm{rpm}$ on a rotatory shaker. Pure cultures were obtained by inoculating Petri dishes containing the same enrichment medium. The potential of different isolates were determined by evaluating glycerol bioconversion in high value-added products (data not shown). The isolate GLC29 showed high potential for glycerol fermentation and was identified as a K. pneumoniae strain using the Enterobacteriaceae identification kit API 20E (Biomerieux, France). The new isolate GLC29 was characterized for ethanol tolerance, growth $\mathrm{pH}$, osmotolerance, and carbon sources used. Cultures were maintained refrigerated in agar slants containing minimal medium, with periodical transference to new media; long time maintenance was performed in cryotubes containing glycerol $40 \%(\mathrm{v} / \mathrm{v})$ at $-20^{\circ} \mathrm{C}$.

\subsection{Glycerol fermentation}

For the preparation of the inoculum, the bacterium K. pneumoniae GLC29 from agar slants was grown in $500 \mathrm{ml}$ Erlenmeyer flasks containing $200 \mathrm{ml}$ of autoclaved $\left(121^{\circ} \mathrm{C} / 15 \mathrm{~min}\right)$ minimal medium ( $\mathrm{g} \mathrm{l}^{-1}$ of deionized water: $\mathrm{NH}_{4} \mathrm{H}_{2} \mathrm{PO}_{4} 5.0, \mathrm{~K}_{2} \mathrm{HPO}_{4} 1.0, \mathrm{MgSO}_{4} \cdot 7 \mathrm{H}_{2} \mathrm{O}$ 0.2 ; $\mathrm{NaCl} 1.0$, yeast extract 1.0 , glycerol 20) and $200 \mu \mathrm{l}$ of trace element solution ( $\mathrm{g} \mathrm{l}^{-1}$ of deionized water: EDTA $0.5, \mathrm{CaCl}_{2} \cdot 2 \mathrm{H}_{2} \mathrm{O} 0.5$, $\mathrm{CoCl}_{2} \cdot 6 \mathrm{H}_{2} \mathrm{O} 0.16, \mathrm{MoNH}_{4} \cdot 4 \mathrm{H}_{2} \mathrm{O} 0.1, \mathrm{CuSO}_{4} \cdot 5 \mathrm{H}_{2} \mathrm{O} 0.16, \mathrm{FeSO}_{4} \cdot 7 \mathrm{H}_{2} \mathrm{O}$ $0.5, \mathrm{MnSO}_{4} \cdot \mathrm{H}_{2} \mathrm{O} 0.5, \mathrm{ZnSO}_{4} \cdot 7 \mathrm{H}_{2} \mathrm{O} \quad 0.22, \mathrm{NiCl}_{2} \cdot 6 \mathrm{H}_{2} \mathrm{O} \quad 0.03, \mathrm{H}_{3} \mathrm{BO}_{3}$ 0.12 ). Seed culture flasks were incubated overnight on a rotatory shaker at $30^{\circ} \mathrm{C}$ and $100 \mathrm{rpm}$.

The fermentation medium was the same as for seed inocula. Glycerol was added in different concentrations, and the $\mathrm{pH}$ was adjusted with $\mathrm{NaOH}$, in agreement with each experiment (Table 1). Batch fermentations were carried out on a 21 reactor containing $500 \mathrm{ml}$ final working volume, with a $5 \%(\mathrm{v} / \mathrm{v})$ inoculum. The $\mathrm{pH}$ was maintained through the automatic addition of $5 \mathrm{M} \mathrm{NaOH}$, and the temperature was controlled by a water bath with microprocessorbased temperature control. The fermentation medium was stirred magnetically with cylindrical stir bars $(12 \mathrm{~mm} \times 55 \mathrm{~mm})$. Each fermentation experiment was run in duplicate or triplicate.

\subsection{Analytical methods}

Fermentation samples were withdrawn periodically for growth monitoring and to determine residual substrates and metabolites. Samples for HPLC were centrifuged (approximately $12,000 \times \mathrm{g} / 8 \mathrm{~min}$ ), and the supernatant was frozen for posterior analysis. Cell growth was monitored at $600 \mathrm{~nm}\left(\mathrm{OD}_{600}\right)$ on a Bel Photonics SP-220 UV/vis spectrophotometer. A standard curve was constructed relating $\mathrm{OD}_{600}$ to cell dry weight $(\mathrm{CDW})$. The $\mathrm{pH}$ was recorded for fermentation monitoring ( $\mathrm{pH}$ rises after carbon source depletion), and $5 \mathrm{M} \mathrm{NaOH}$ consumption was recorded for the correction of dilution due to base addition in the reactors. Residual substrate and metabolites (succinate, lactate, formate, 
acetate, ethanol, 1,3-propanediol, and 2,3-butanediol) were quantified through high-performance liquid chromatography (HPLC Thermo Separation Products) equipped with an in-line UV/vis and RI detectors and an ion-exchange column $(300 \mathrm{~mm} \times 7.8 \mathrm{~mm}$ Rezex Roa organic acid - Phenomenex, Torrance, CA, USA). The samples were run at $60^{\circ} \mathrm{C}$ and the mobile phase was $0.005 \mathrm{M}$ $\mathrm{H}_{2} \mathrm{SO}_{4}$ at $0.4 \mathrm{ml} \mathrm{min}^{-1}$.

\subsection{Experimental design}

The central composite design (CCD) was performed to test the effect of the independent variables $\mathrm{pH}$, temperature, stirrer speed, and glycerol concentration on the production and productivity of 1,3-PDO by K. pneumoniae GLC29 using glycerol as the only carbon and energy source. Each independent variable was arranged at five levels with eight star points and three replicates at the center point. A second order polynomial model was used to determine the optimal interval of each variable for 1,3-PDO production and productivity. The variables of the experiments were coded according to the following equation:

$x_{i}=\frac{X_{i}-X_{c p}}{\Delta X_{i}}$ where $i=1,2, \ldots, K$

where $x_{i}$ is the coded value of an independent variable; $X_{i}$ is the real value of an independent variable; $X_{c p}$ is the real value of an independent variable at the center point; and $\Delta X_{i}$ is the step change value.

The behavior of the system was explained by the following quadratic equation:

$Y=B_{0}+\sum B_{i} X_{i}+\sum B_{i i} X_{i 2}+\sum B_{i j} X_{i} X_{j}$

where $Y$ is the predicted response, i.e., 1,3-PDO concentration and/or productivity; $B_{0}$ is the offset term; $B_{i}$ is the linear effect; $B_{i i}$ is the squared effect; and $B_{i j}$ is the interaction effect. $X_{i}$ is $i$ th independent variable. A total of 27 experiments were carried out
Table 1

Experimental range and levels of the independent variables used in central composite design

\begin{tabular}{lllrrrr}
\hline Independent variables & \multicolumn{7}{c}{ Range and levels } \\
\cline { 2 - 7 } & & \multicolumn{1}{c}{$\alpha$} & \multicolumn{1}{c}{-1} & \multicolumn{1}{c}{0} & \multicolumn{1}{c}{+1} & \multicolumn{1}{c}{$+\alpha$} \\
\hline pH & $X_{1}$ & 5.5 & 6.0 & 6.5 & 7.0 & 7.5 \\
Temperature $\left({ }^{\circ} \mathrm{C}\right)$ & $X_{2}$ & 26.5 & 30 & 33.5 & 37 & 40.5 \\
Agitation $(\mathrm{rpm})$ & $X_{3}$ & 70 & 120 & 170 & 220 & 270 \\
Glycerol $\left(\mathrm{g} \mathrm{l}^{-1}\right)$ & $X_{4}$ & 15 & 25 & 35 & 45 & 55 \\
\hline
\end{tabular}

using the CCD method, with five levels each, namely $\mathrm{pH}\left(X_{1}\right)$, temperature $\left(X_{2}\right)$, stirrer speed $\left(X_{3}\right)$, and glycerol concentration $\left(X_{4}\right)$ (Tables 1 and 2).

\subsubsection{Statistical analysis}

The Statistica 7.0 software package (StatSoft, Tulsa, USA) was used for the experimental design and regression analysis of the experimental data. Response surface and contour plots were generated to understand the interaction between different variables. Statistical analysis of the model was performed to evaluate the analysis of variance (ANOVA). The quality of the polynomial model equation was statistically tested by the coefficient of determination $R^{2}$ and the statistical significance determined by an $F$-test. The significance of the regression coefficients was tested by a $t$-test.

\section{Results}

\subsection{K. pneumoniae GLC29}

The isolated GLC29 showed a high potential for glycerol fermentation. GLC29 was isolated from bryophytes collected near the soil, growing at the base of Terminalia catappa and was identified as a newly isolated $K$. pneumoniae strain. This bacterium grows quickly in minimal medium containing only glycerol as its

Table 2

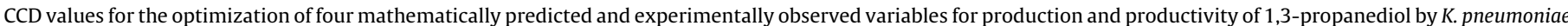
GLC29 using glycerol.

\begin{tabular}{|c|c|c|c|c|c|c|c|c|}
\hline \multirow[t]{3}{*}{ Essay } & \multirow{3}{*}{$\begin{array}{l}\mathrm{pH} \\
X_{1}\end{array}$} & \multirow{3}{*}{$\begin{array}{l}\text { Temperature }\left({ }^{\circ} \mathrm{C}\right) \\
X_{2}\end{array}$} & \multirow{3}{*}{$\begin{array}{l}\text { Stirrer speed (rpm) } \\
X_{3}\end{array}$} & \multirow{3}{*}{$\begin{array}{l}\text { Glycerol }\left(\mathrm{g} \mathrm{l}^{-1}\right) \\
X_{4}\end{array}$} & \multicolumn{4}{|c|}{ 1,3-Propanediol } \\
\hline & & & & & \multicolumn{2}{|c|}{ Production $\left(\mathrm{g} \mathrm{l}^{-1}\right)$} & \multicolumn{2}{|c|}{ Productivity $\left(\mathrm{gl}^{-1} \mathrm{~h}^{-1}\right)$} \\
\hline & & & & & Observed & Expected & Observed & Expected \\
\hline 1 & 6.0 & 30.0 & 120 & 25 & 13.22 & 12.33 & 1.47 & 1.66 \\
\hline 2 & 6.0 & 30.0 & 120 & 45 & 21.88 & 20.92 & 1.62 & 1.29 \\
\hline 3 & 6.0 & 30.0 & 220 & 25 & 14.30 & 13.5 & 1.94 & 2.17 \\
\hline 4 & 6.0 & 30.0 & 220 & 45 & 22.91 & 22 & 1.62 & 1.67 \\
\hline 5 & 6.0 & 37.0 & 120 & 25 & 14.19 & 12.17 & 1.95 & 1.89 \\
\hline 6 & 6.0 & 37.0 & 120 & 45 & 20.98 & 20.14 & 2.22 & 2.25 \\
\hline 7 & 6.0 & 37.0 & 220 & 25 & 12.53 & 11.54 & 2.04 & 1.76 \\
\hline 8 & 6.0 & 37.0 & 220 & 45 & 20.50 & 19.43 & 1.84 & 1.99 \\
\hline 9 & 7.0 & 30.0 & 120 & 25 & 13.10 & 12.99 & 2.46 & 2.17 \\
\hline 10 & 7.0 & 30.0 & 120 & 45 & 23.55 & 23.91 & 2.82 & 3.13 \\
\hline 11 & 7.0 & 30.0 & 220 & 25 & 11.98 & 12.19 & 1.93 & 1.92 \\
\hline 12 & 7.0 & 30.0 & 220 & 45 & 22.19 & 23.02 & 2.82 & 2.74 \\
\hline 13 & 7.0 & 37.0 & 120 & 25 & 14.09 & 14.37 & 3 & 2.97 \\
\hline 14 & 7.0 & 37.0 & 120 & 45 & 25.05 & 24.67 & 5.03 & 4.66 \\
\hline 15 & 7.0 & 37.0 & 220 & 25 & 11.99 & 11.77 & 1.89 & 2.08 \\
\hline 16 & 7.0 & 37.0 & 220 & 45 & 21.73 & 21.99 & 3.8 & 3.63 \\
\hline 17 & 5.5 & 33.5 & 170 & 35 & 10.29 & 13.62 & 1.33 & 1.28 \\
\hline 18 & 7.5 & 33.5 & 170 & 35 & 18.36 & 16.84 & 3.27 & 3.43 \\
\hline 19 & 6.5 & 26.5 & 170 & 35 & 17.01 & 17.24 & 1.86 & 1.76 \\
\hline 20 & 6.5 & 40.5 & 170 & 35 & 14.45 & 16.04 & 2.66 & 2.87 \\
\hline 21 & 6.5 & 33.5 & 70 & 35 & 18.25 & 19.62 & 2.98 & 3.19 \\
\hline 22 & 6.5 & 33.5 & 270 & 35 & 17.65 & 18.1 & 2.78 & 2.68 \\
\hline 23 & 6.5 & 33.5 & 170 & 15 & 7.73 & 9.1 & 1.34 & 1.31 \\
\hline 24 & 6.5 & 33.5 & 170 & 55 & 27.46 & 27.91 & 2.35 & 2.49 \\
\hline $25 \mathrm{C}$ & 6.5 & 33.5 & 170 & 35 & 18.96 & 19.21 & 3.36 & 3.53 \\
\hline $26 C$ & 6.5 & 33.5 & 170 & 35 & 19.89 & 19.21 & 3.96 & 3.53 \\
\hline $27 C$ & 6.5 & 33.5 & 170 & 35 & 18.78 & 19.21 & 3.28 & 3.53 \\
\hline
\end{tabular}


Table 3

Model coefficient estimated by multiple linear regression for 1,3-propanediol production by Klebsiella pneumoniae GLC29.

\begin{tabular}{lrlrl}
\hline Factor & $\begin{array}{l}\text { Regression } \\
\text { coefficient }\end{array}$ & $\begin{array}{l}\text { Standard } \\
\text { error }\end{array}$ & $t$ value & $P$ value \\
\hline Intercept & 19.2100 & 0.9452 & 20.3237 & 0.0000 \\
$X_{1}$ & 0.8046 & 0.3342 & 2.4076 & 0.0330 \\
$X_{1}^{2}$ & -0.9943 & 0.3544 & -2.8051 & 0.0158 \\
$X_{2}$ & -0.2996 & 0.3342 & -0.8964 & 0.3876 \\
$X_{2}^{2}$ & -0.6430 & 0.3544 & -1.8141 & 0.0947 \\
$X_{3}$ & -0.3804 & 0.3342 & -1.1383 & 0.2772 \\
$X_{3}^{2}$ & -0.0880 & 0.3544 & -0.2483 & 0.8080 \\
$X_{4}$ & 4.7020 & 0.3342 & 14.0705 & 0.0000 \\
$X_{4}^{2}$ & -0.1767 & 0.3544 & -0.4987 & 0.6269 \\
$X_{1} X_{2}$ & 0.3844 & 0.4093 & 0.9391 & 0.3661 \\
$X_{1} X_{3}$ & -0.4918 & 0.4093 & -1.2018 & 0.2526 \\
$X_{1} X_{4}$ & 0.5831 & 0.4093 & 1.4247 & 0.1797 \\
$X_{2} X_{3}$ & -0.4494 & 0.4093 & -1.0979 & 0.2937 \\
$X_{2} X_{4}$ & -0.1543 & 0.4093 & -0.3772 & 0.7126 \\
$X_{3} X_{4}$ & -0.0206 & 0.4093 & -0.0504 & 0.9606 \\
\hline
\end{tabular}

$X_{1}=\mathrm{pH} ; X_{2}=$ temperature; $X_{3}=$ agitation; $X_{4}=$ glycerol concentration. Meaningful values at $95 \%$ confidence are in italics.

carbon and energy source. GLC29 grows between pH 4 and 10, with optimal growth between $\mathrm{pH} 5$ and 8 . $\mathrm{NaCl}$ osmotolerance varies between 0 and $4.0 \%(\mathrm{p} / \mathrm{v})$ after $24 \mathrm{~h}$ of incubation, but still grows in higher $\mathrm{NaCl}$ concentrations when incubated for a longer time, that is, $5.5 \%$ in $44 \mathrm{~h}$, up to a maximum of $6.5 \%$ in $72 \mathrm{~h}$, and not growing in higher $\mathrm{NaCl}$ concentrations. K. pneumoniae GLC29 grows in up to $8 \%$ ethanol in mineral medium containing a glycerol concentration of $20 \mathrm{~g} \mathrm{l}^{-1}$. In a phenol red carbohydrate broth containing Durham tubes, this bacterium produces acid and gas from the following tested carbon sources: glucose, xylose, sucrose, maltose, lactose, mannitol, mannose, sorbitol, and glycerol. The products from glycerol fermentation are the 1,3-PDO, 2,3-BDO, ethanol, and the organic acids acetate, formate, lactate, and succinate.

\subsection{Production of 1,3-propanediol by K. pneumoniae GLC29}

Preliminary fermentations in a rotatory shaker showed that GLC29 consumed glycerol quickly, converting it to 1,3-propanediol as the main fermentation product (data not shown). The central composite design was used to determine values of $\mathrm{pH}$, temperature, agitation, and glycerol concentration for optimal bioconversion of this substrate to 1,3-PDO. Linear and quadratic effects of each variable and the effect of interaction between them on 1,3-PDO production and productivity were analyzed. Table 2 presents the matrix of experiments, observed and expected production $\left(\mathrm{gl}^{-1}\right)$, and productivity $\left(\mathrm{gl}^{-1} \mathrm{~h}^{-1}\right)$ of 1,3-PDO. Results of the dependent variable were used to determine regression coefficients for 1,3-PDO production (Table 3), to calculate ANOVA (Table 4), and to construct response surface and contour plots (Fig. 1) for significant results. Eq. (3) is presented the complete equation as a function ofregression coefficients for 1,3-PDO production.

$$
\begin{aligned}
Y_{(\text {Production })=} & 19.210+0.804 X_{1}-0.299 X_{2}-0.380 X_{3}+4.702 X_{4} \\
& +0.384 X_{1} X_{2}-0.491 X_{1} X_{3}+0.583 X_{1} X_{4}-0.449 X_{2} X_{3} \\
& -0.154 X_{2} X_{4}-0.020 X_{3} X_{4}-0.994 X_{1} X_{1}-0.643 X_{2} X_{2} \\
& -0.088 X_{3} X_{3}-0.176 X_{4} X_{4}
\end{aligned}
$$

The quadratic model in Eq. (3) with fourteen terms contains four linear terms, six factorial interactions and four quadratic terms, where $Y_{\text {(Production) }}$ is the predicted response, i.e., the 1,3-PDO concentration in the fermentation medium, and $X_{1}, X_{2}, X_{3}$, and $X_{4}$ are respectively the coded values of the tested variables $\mathrm{pH}$, temperature, stirrer speed, and glycerol concentration.

Table 3 shows the Student's $t$ distribution and the corresponding values, along with the estimated parameters. The probability $(P)$ values were used as a tool to check the significance of each coefficient. A larger magnitude of the $t$-test and a smaller $P$-value denote greater significance of the corresponding coefficient. As seen in Table 3 , temperature of fermentation $\left(X_{2}\right)$ and stirrer speed $\left(X_{3}\right)$ had no effect on the final 1,3-PDO concentration, while the independent variables $\mathrm{pH}\left(X_{1}\right)$ and glycerol concentration $\left(X_{4}\right)$ had a strong positive linear effect on the response $(P<0.05)$. The same is observed with the squared variable $\left(X_{1}^{2}\right)$, where the negative sign revealed a reduction in 1,3-propanediol production when $\mathrm{pH}$ was increased in the system. The non-significant terms (on the basis of $P$-values above 0.05) were neglected, and the model Eq. (3) was modified to the reduced fitted model ( $\left.Y_{\text {Adjusted production }}\right)$ of Eq. (4).

$Y_{\text {Adjusted production }}=18.241+0.804 X_{1}+4.702 X_{4}-0.812 X_{1} X_{1}$

The statistical significance of Eq. (4) was checked using an $F$ test and the analysis of variance (ANOVA) for the response surface quadratic model, which is summarized in Table 4. Fisher's F-test $\left(F_{(14,12)}=S_{\mathrm{m}}^{2} / S_{\mathrm{S}}^{2}=15.828>\mathrm{Ft}_{(14,12)}=2.62\right.$ with a very low probability value $\left[\left(P_{\text {model }}>F\right)<0.0000\right]$ indicated that the model was significant. The goodness-of-fit of the model was checked by the determination coefficient $\left(R^{2}\right)$ and the multiple correlation coefficient $(R)$. In this case, the $R^{2}$ value (0.943) indicates that the sample variation of $94.3 \%$ for 1,3 -propanediol was attributed to the independent variables, and only $5.7 \%$ of the total variation cannot be explained by the model. The adjusted determination coefficient (Adj. $R^{2}=0.888$ ) was also satisfactory for confirming the significance of the model.

The surface and contour plots were constructed from the ANOVA results (Table 4), showing the best $\mathrm{pH}$ interval for 1,3-PDO production and the interaction effect between $\mathrm{pH}$ and glycerol concentration (Fig. 1). Analysis of Fig. 1 shows that the best $\mathrm{pH}$ interval for glycerol conversion in 1,3-PDO was 6.4-7.1, and a higher production of 1,3-PDO occurred in higher concentrations of glycerol, in spite of the fact that productivity is negatively affected by high

\begin{tabular}{|c|c|c|c|c|c|}
\hline Source & Sum of squares & Degrees of freedom & Mean square & $F$ value & $P>F$ \\
\hline Model & 593.9063 & 14 & 42.4218 & 15.8278 & 0.0000 \\
\hline Residual & 32.1624 & 12 & 2.6802 & & \\
\hline Lack of Fit & 21.5609 & 9 & 2.3957 & 6.750 & 0.1356 \\
\hline Pure error & 0.7098 & 2 & 0.3549 & & \\
\hline Total & 626.0688 & 26 & & & \\
\hline
\end{tabular}
glycerol concentrations, as can be seen in the following section.

Table 4

Analysis of variance of the quadratic model for 1,3-propanediol yield by Klebsiella pneumoniae GLC29 using glycerol. 

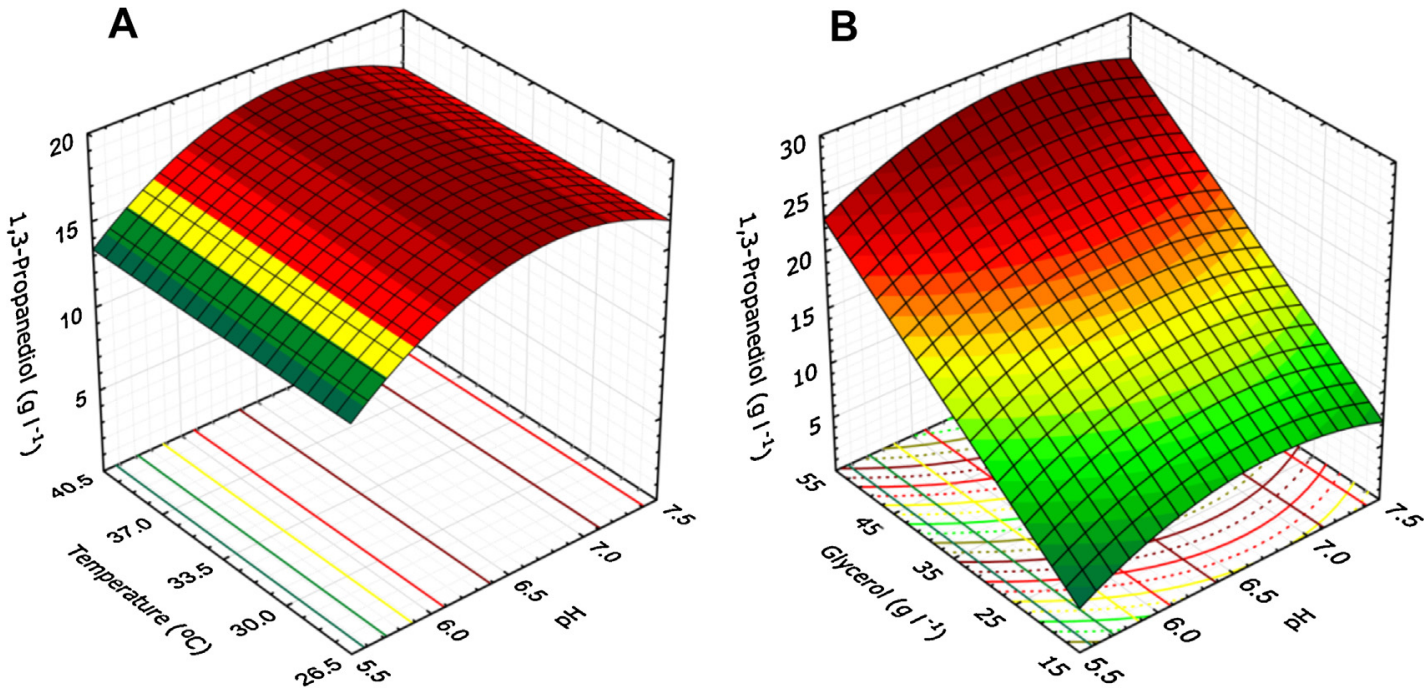

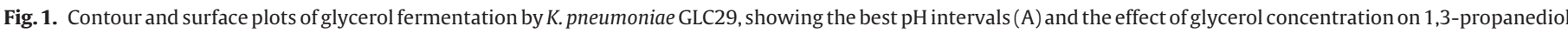
production (B). Temperature and stirrer speed were not significant for fermentation.

\subsection{Productivity of 1,3-propanediol by K. pneumoniae GLC29}

Glycerol bioconversion in 1,3-PDO was also analyzed with respect to maximum productivity, determined in the interval of time where the largest slope of the straight line plotting 1,3-PDO productivity versus fermentation time was observed. The results for productivity, observed and predicted by the statistical model, are shown in Table 2. At 95\% probability, there were statistically significant effects on 1,3-PDO productivity from $\mathrm{pH}$, temperature, glycerol concentration, and the quadratic coefficients of all independent variables, and interactions between $\mathrm{pH}$ and stirrer speed, $\mathrm{pH}$ and glycerol concentration, and temperature and glycerol concentration (Table 5). Table 6 presents regression coefficients for the productivity of 1,3-PDO by K. pneumoniae GLC29 using glycerol.

In order to determine the maximum 1,3-propanediol productivity corresponding to the optimum interval of $\mathrm{pH}$, temperature, stirrer speed, and glycerol concentration, a second order polynomial model was proposed to calculate the optimum levels of these variables. By applying a multiple regression analysis on experimental data, a second order polynomial model explains the role of each variable and their second order interactions in producing 1,3-PDO. The quadratic model in Eq. (5) with 14 terms contains four linear

Table 5

Model coefficient estimated by multiple linear regression for 1,3-propanediol productivity by Klebsiella pneumoniae GLC29.

\begin{tabular}{lclrl}
\hline Factor & $\begin{array}{l}\text { Regression } \\
\text { coefficient }\end{array}$ & $\begin{array}{l}\text { Standard } \\
\text { error }\end{array}$ & Computed $t$ value & $P$ value \\
\hline Intercept & 3.5333 & 0.1771 & 19.9496 & 0.0000 \\
$X_{1}$ & 0.5387 & 0.0626 & 8.6036 & 0.0000 \\
$X_{1}^{2}$ & -0.2946 & 0.0664 & -4.4369 & 0.0008 \\
$X_{2}$ & 0.2787 & 0.0626 & 4.4515 & 0.0007 \\
$X_{2}^{2}$ & -0.3046 & 0.06647 & -4.5875 & 0.0006 \\
$X_{3}$ & -0.1287 & 0.0626 & -2.0561 & 0.0621 \\
$X_{3}^{2}$ & -0.1496 & 0.0664 & -2.2537 & 0.0437 \\
$X_{4}$ & 0.2962 & 0.0626 & 4.7310 & 0.0004 \\
$X_{4}^{2}$ & -0.4084 & 0.0664 & -6.1495 & 0.0000 \\
$X_{1} X_{2}$ & 0.1431 & 0.0767 & 1.8662 & 0.0866 \\
$X_{1} X_{3}$ & -0.1906 & 0.0767 & -2.4856 & 0.0286 \\
$X_{1} X_{4}$ & 0.3306 & 0.0767 & 4.3111 & 0.0010 \\
$X_{2} X_{3}$ & -0.1606 & 0.0767 & -2.0944 & 0.0581 \\
$X_{2} X_{4}$ & 0.1831 & 0.0767 & 2.3878 & 0.0342 \\
$X_{3} X_{4}$ & -0.0331 & 0.0767 & -0.4319 & 0.6734 \\
\hline$X_{1}$ & & &
\end{tabular}

$X_{1}=\mathrm{pH}, X_{2}=$ temperature, $X_{3}=$ stirrer speed, $X_{4}=$ glycerol concentration. Meaningful values at $95 \%$ confidence are in italic. terms, six factorial interactions, and four quadratic terms.

$$
\begin{aligned}
Y_{(\text {Productivity })=} & 3.533+0.539 X_{1}+0.279 X_{2}-0.129 X_{3}+0.296 X_{4} \\
& +0.143 X_{1} X_{2}-0.191 X_{1} X_{3}+0.331 X_{1} X_{4} \\
& -0.161 X_{2} X_{3}+0.183 X_{2} X_{4}-0.033 X_{3} X_{4} \\
& -0.295 X_{1} X_{1}-0.305 X_{2} X_{2}-0.150 X_{3} X_{3} \\
& -0.408 X_{4} X_{4}
\end{aligned}
$$

Non-significant terms (on the basis of $P$-values above 0.05 as shown in Table 5) were neglected and the model Eq. (5) was modified to the reduced fitted model Eq. (6):

$$
\begin{aligned}
Y_{(\text {Adjusted productivity })=} & 3.533+0.539 X_{1}+0.279 X_{2}+0.296 X_{4} \\
& -0.191 X_{1} X_{3}+0.331 X_{1} X_{4}-0.161 X_{2} X_{3} \\
& +0.183 X_{2} X_{4}-0.295 X_{1} X_{1}-0.305 X_{2} X_{2} \\
& -0.150 X_{3} X_{3}-0.408 X_{4} X_{4}
\end{aligned}
$$

Surface and contour plots for interaction effects between independent variables were constructed from ANOVA results (Table 6). The model can be considered suitable because the percentage of variation explained is $94.5 \%$ for the complete equation and $88.2 \%$ for the adjusted model. The Fisher's F-test $\left(F_{(14,12)}=S_{\mathrm{m}}^{2} / S_{\mathrm{S}}^{2}=14.892>\mathrm{Ft}_{(14,12)}=2.62\right.$ with a very low probability value $\left[\left(P_{\text {model }}>F\right)<0.0000\right]$ indicated that the model was significant. These results allowed defining the best intervals for independent variables to obtain the highest 1,3-PDO productivity

Table 6

Analysis of variance for 1,3-propanediol productivity by Klebsiella pneumoniae GLC29 from glycerol.

\begin{tabular}{lrllll}
\hline Source & $\begin{array}{c}\text { Sum of } \\
\text { squares }\end{array}$ & $\begin{array}{l}\text { Degrees of } \\
\text { freedom }\end{array}$ & $\begin{array}{l}\text { Mean } \\
\text { square }\end{array}$ & $F$ value & $P>F$ \\
\hline Model & 19.6194 & 14 & 1.4013 & 14.8915 & 0.0000 \\
Residual & 1.1293 & 12 & 0.0941 & & \\
Lack of fit & 15.7774 & 19 & 0.8304 & 6.0115 & 0.1521 \\
Pure error & 0.2762 & 2 & 0.1381 & & \\
Total & 20.7486 & 26 & & & \\
\hline
\end{tabular}

$R^{2}=0.945$, Adj. $R^{2}=0.882$. 

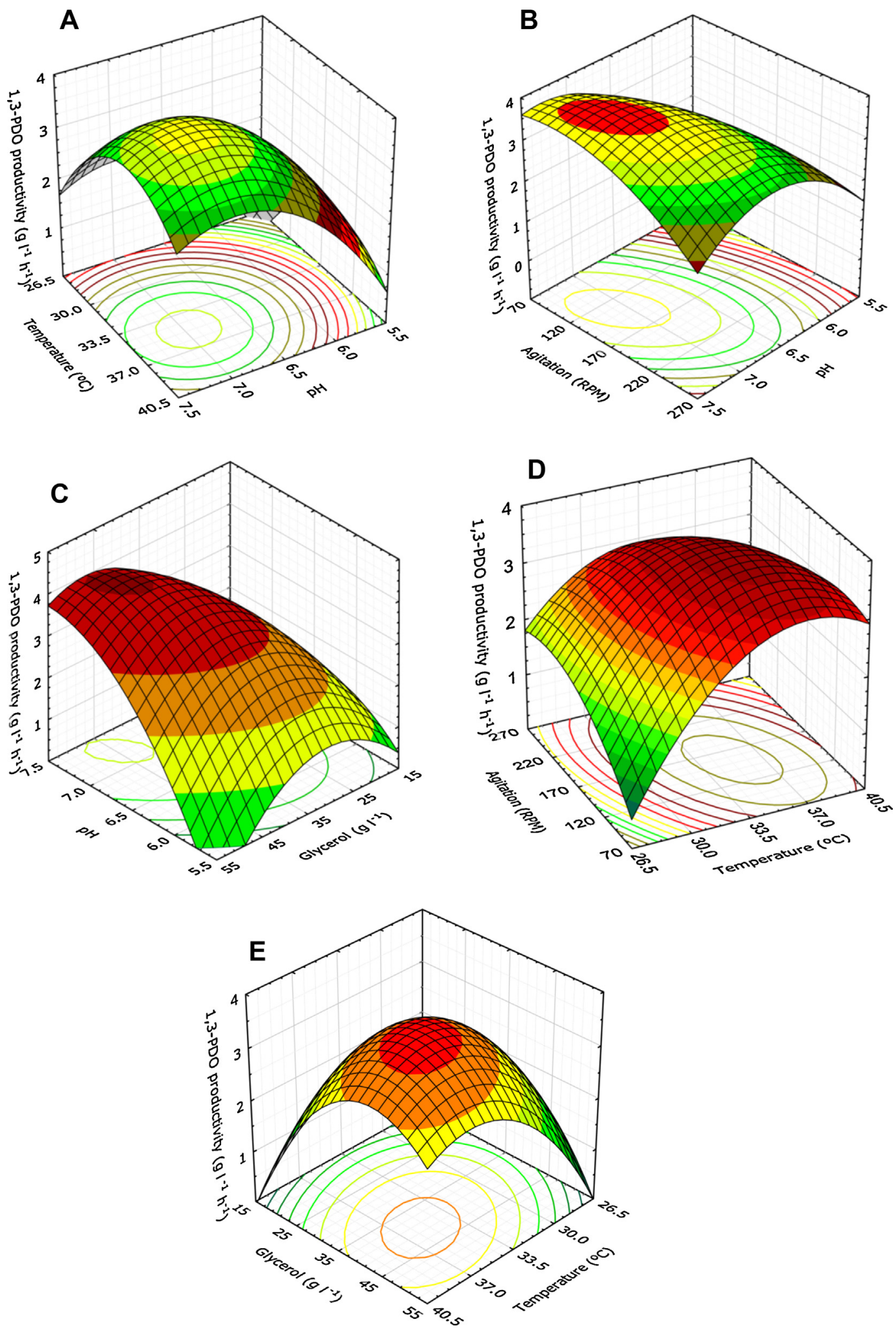

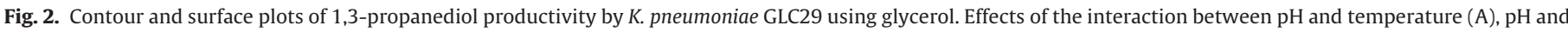
agitation (B), glycerol and $\mathrm{pH}(\mathrm{C})$, temperature and agitation (D) and temperature and glycerol (E).

(Fig. 2). Analyzing contour and surface plots, the best intervals for higher 1,3-PDO productivity were as follows: a pH between 6.7 and 7.5 (Fig. $2 \mathrm{a}-\mathrm{C}$ ), a temperature ranging from 33 to $38.5^{\circ} \mathrm{C}$ (Fig. 2a, $\mathrm{d}$ and e), a stirrer speed ranging from 110 to $180 \mathrm{rpm}$ (Fig. $2 \mathrm{~b}$ and $\mathrm{d}$ ), and a glycerol concentration between 39 and $49 \mathrm{gl}^{-1}$ (Fig. 2c and e). Considering these results, batch fermentation was carried out using the best intervals for 1,3-PDO production and productivity. 


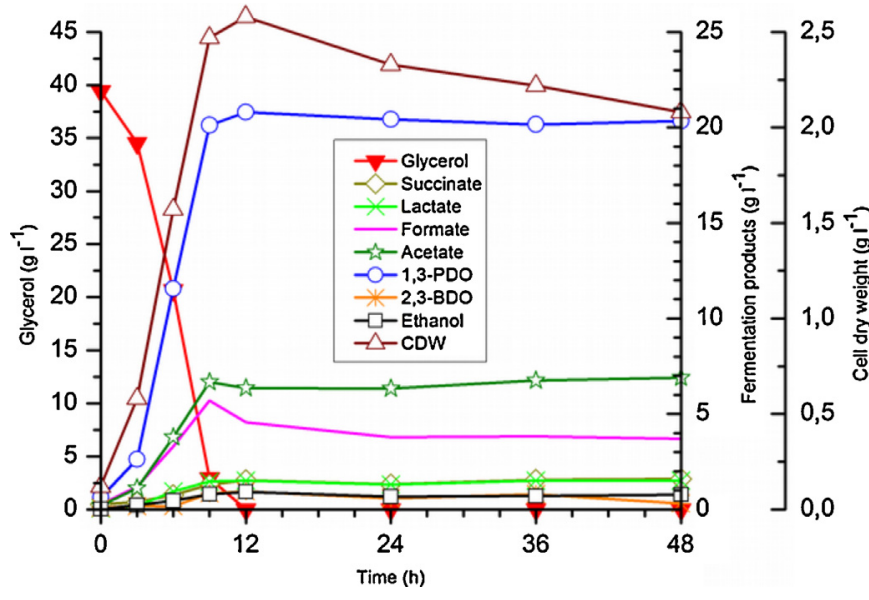

Fig. 3. Batch glycerol fermentation by K. pneumoniae $\mathrm{GLC} 29$ at $\mathrm{pH} 7.0,35^{\circ} \mathrm{C}, 150 \mathrm{rpm}$ and $40 \mathrm{~g}$ of glycerol $\mathrm{l}^{-1}$.

\subsection{Batch fermentation}

Considering the results obtained for production $\left(\mathrm{g} \mathrm{l}^{-1}\right)$ and productivity $\left(\mathrm{gl}^{-1} \mathrm{~h}^{-1}\right)$ of $1,3-P D O$ by $K$. pneumoniae GLC29 using glycerol, batch fermentation was performed at a $\mathrm{pH} 7.0$, a temperature of $35^{\circ} \mathrm{C}$, a stirrer speed of $150 \mathrm{rpm}$ and a glycerol concentration of $40 \mathrm{gl}^{-1}$, which are within the optimal intervals for both parameters as seen in Figs. 1 and 2. In these conditions, GLC29 grew well producing about $2.5 \mathrm{~g} \mathrm{CDW}^{-1}$. Glycerol was quickly consumed, taking just over $9 \mathrm{~h}$ of fermentation (Fig. 3). The final concentration of 1,3-PDO was about $20.4 \mathrm{gl}^{-1}$, with a yield of $0.51 \mathrm{~g}$ 1,3-PDO/g glycerol. Maximal productivity was $2.92 \mathrm{~g} \mathrm{l}^{-1} \mathrm{~h}^{-1}$, and the maximum rate of consumption of glycerol was $5.26 \mathrm{gl}^{-1} \mathrm{~h}^{-1}$. The main byproducts obtained were acetic acid (approximately $7 \mathrm{gl}^{-1}$ ) and formate (approximately $3.7 \mathrm{gl}^{-1}$ ). Small amounts of succinate (approximately $1.59 \mathrm{~g} \mathrm{l}^{-1}$ ) and lactate $\left(1.51 \mathrm{gl}^{-1}\right)$ were produced. The production of 2,3-BDO and ethanol was less than $1.0 \mathrm{gl}^{-1}$.

\section{Discussion}

The bacteria K. pneumoniae and C. butyricum are the most efficient microbial producers of 1,3-PDO using glycerol. Recently, these bacteria have been extensively studied for industrial applications in glycerol fermentation for their high production and productivity. In this work, preliminary batch fermentations in Erlenmeyer flasks and a rotatory shaker showed a new strain to be efficient in fermenting glycerol. This microorganism was identified as K. pneumoniae strain GLC29. The fermentation products were 1,3-PDO, 2,3-BDO, ethanol, acetate, lactate, succinate, and formate. In order to optimize the conditions for 1,3-PDO production, response surface methodology was performed to determine the effect of the independent variables $\mathrm{pH}$, temperature, stirrer speed, and glycerol concentration on 1,3-PDO production and productivity.

The fermentation temperature and stirrer speed had no significant effect on 1,3-PDO production from glycerol, while the best $\mathrm{pH}$ was between 6.4 and 7.1. A higher production of 1,3-PDO occurred in higher concentrations of glycerol (Fig. $1 \mathrm{a}$ and $\mathbf{b}$ and Table 3 ). The fact that temperature did not interfere significantly with the 1,3-PDO concentration is interesting for industrial applications, because it allows working within a wide range of temperatures without losing yield in the process, reducing the cost of fermentation with respect to processes for which strict control of this parameter is required. However, productivity is negatively affected by both high and low temperatures. These results are in accordance with Rossi et al. [20], who observed that the variation of temperature had shown no effect on 1,3-PDO production by $K$. pneumoniae Blh-1. The results for temperature and $\mathrm{pH}$ for 1,3-PDO production found in this work is different from that of Zhang et al. [32], who observed that optimal cultivation parameters for temperature and $\mathrm{pH}$ using $\mathrm{K}$. pneumoniae $\mathrm{XJ}$-Li were $40^{\circ} \mathrm{C}$ and $\mathrm{pH}$ 8.0 , respectively. Zhang et al. [32] obtained $12.2 \mathrm{~g}$ of $1,3-\mathrm{PDOl}^{-1}$ from $20 \mathrm{~g}_{\text {glycerol }} \mathrm{l}^{-1}$ consumed in about $8 \mathrm{~h}$, with a productivity of $1.53 \mathrm{~g} \mathrm{l}^{-1} \mathrm{~h}^{-1}$ and a yield of $0.75 \mathrm{~mol} \mathrm{~mol}^{-1}\left(0.61 \mathrm{~g} \mathrm{~g}^{-1}\right)$. In batch fermentation at $\mathrm{pH} 7.0$ and $35^{\circ} \mathrm{C}, \mathrm{K}$. pneumoniae GLC29 produced $20.4 \mathrm{~g}$ of $1,3-\mathrm{PDO} \mathrm{I}^{-1}$ from $40 \mathrm{~g}$ glycerol $\mathrm{l}^{-1}$ consumed in about $9 \mathrm{~h}$, with $2.92 \mathrm{~g} \mathrm{l}^{-1} \mathrm{~h}^{-1}$ of maximal productivity and a yield of $0.51 \mathrm{~g}$ $1,3-\mathrm{PDO} \mathrm{g}^{-1}$ glycerol $\left(0.61 \mathrm{~mol} \mathrm{~mol}^{-1}\right)$. The difference in $\mathrm{pH}$ found between the XJ-Li and GLC29 strains could be explained by the origin of the isolates, since $\mathrm{XJ}$-Li was isolated from micro-alkaline soil. A negative effect on 1,3-PDO production when $\mathrm{pH}$ was increased was also observed by Rossi et al. [20].

The $\mathrm{pH}$ is one of the parameters that determines the profile products in fermentation. For example, 2,3-BDO formation starts at $\mathrm{pH} 6.6$ and reaches a maximum yield at $\mathrm{pH} 5.5$, thereby producing fewer toxic products such as alcohols or glycols as a strategy to escape progressive acidity of the medium [33]. However, when acetate (and formate) is the main byproduct of fermentation, the 1,3-PDO yield is higher, because conversion of pyruvate to acetate produces ATP but does not consume the reducing equivalents (NADH) required for 1,3-PDO production [24,34]. In order to minimize the formation of 2,3-BDO (produced between $\mathrm{pH} 5.0$ and 6.5) and lactic acid (produced between pH 7.1 and 8.0), Ji et al. [35] evaluated the production of 1,3-PDO, periodically alternating the $\mathrm{pH}$ of the medium to between 6.3 and 7.3 during fermentation. The best results obtained were $70 \mathrm{~g}$ of $1,3-\mathrm{PDOl}^{-1}$, a yield of $0.70 \mathrm{~mol} \mathrm{~mol}^{-1}$, and a productivity of $0.97 \mathrm{~g} \mathrm{l}^{-1} \mathrm{~h}^{-1}$, with low concentrations of 2,3$\mathrm{BDO}$ and lactate. Another parameter that increases lactate as well as 2,3-BDO production is an excess of glycerol in the medium [24,33].

The best intervals for a higher 1,3-PDO productivity were between $\mathrm{pH} 6.7$ and 7.5, a temperature range of 33 and $38.5^{\circ} \mathrm{C}$, a stirrer speed of 110-180 rpm, and a glycerol concentration of between 39 and $49 \mathrm{gl}^{-1}$. When considering medium agitation, a higher stirrer speed is harmful to productivity, probably due to a higher aeration of the medium, which impairs fermentation. According to Biebl et al. [33], at a neutral pH the 1,3-PDO formation is reduced in the presence of oxygen, which is probably caused by the oxygen sensitivity of the two enzymes of the 1,3PDO pathway. The authors speculate that under microaerobiosis and low pH, glycerol is converted to 2,3-BDO only, i.e., the NADH is recycled by oxygen and no longer by glycerol. According to Seifert et al. [36], inactivation of diol dehydratase by $\mathrm{O}_{2}$ in the absence of a substrate occurs by a reaction of the activated $\mathrm{Co}-\mathrm{C}$ bond of the enzyme-bound coenzyme $\mathrm{B}_{12}$ with $\mathrm{O}_{2}$. Hongwen et al. [37] recorded maximal activity of key enzymes for 1,3-PDO production at pH 7.0 and that adequate oxygen favors cell growth, whereas excess oxygen is not suitable for accumulation of 1,3-PDO. Activity of the three key enzymes and biomass increased with shaker speed, with maximum biomass and activities of GDH and PDOR attained with a shaker speed of $200 \mathrm{rpm}$. Maximal activities of key enzymes were obtained at $37^{\circ} \mathrm{C}$; in temperatures above $37^{\circ} \mathrm{C}$, biomass and activities greatly decreased [37].

Productivity decreases with lower and higher glycerol concentrations. At high concentrations, glycerol could pass the cell membrane by passive diffusion, and at low concentrations, by glycerol facilitators [38]. Low substrate concentration has an obvious effect on transport across the cell membrane and, consequently, there is little substrate remaining for enzymatic reactions. At high concentrations, the enzyme glycerol dehydratase (GDHt, E.C. 4.2.1.30, convert glycerol to 3-hydroxypropionaldehyde) is the limiting step for the consumption of glycerol and consequently to produce 1,3PDO in K. pneumoniae [39]. However, GDHt is subject to suicide 
inactivation by glycerol during catalysis, which involves irreversible cleavage of the $\mathrm{Co}-\mathrm{C}-\mathrm{C}$ bond of the coenzyme $\mathrm{B}_{12}$, forming 5 '-deoxyadenosine and an alkylcobalamin-like species [36].

The newly isolated K. pneumoniae GLC29 strain contains several characteristics of a good industrial strain. For example, glycerol was fermented without strict anaerobic conditions, and no rich nutrient was required for fermentation. These characteristics make the fermentation process less expensive, which is pursued in industrial strains. Nevertheless, there are possibilities for better fermentation results, evaluating new medium compositions, supplementations, use of co-substrates, inocula, and by genetic engineering. Currently, the excess of glycerol produced as a byproduct of the biodiesel industry is of global concern, and several alternatives are being researched. One of the potential applications is to use glycerol as a carbon source in industrial microbiology to obtain products of high added value, and 1,3-propanediol appears to be one of the most promising alternatives. In this study, K. pneumoniae GLC29 presented a high potential for industrial application.

\section{Acknowledgments}

This work was financially supported by the Banco do Nordeste do Brasil (BNB) (grant no. BNB/Uneb 059/2007) and the Fundação de Amparo a Pesquisa do Estado da Bahia (Fapesb) (grant no. PES 0072/2008).

\section{References}

[1] G.P. da Silva, M. Mack, J. Contiero, Biotechnol. Adv. 27 (2009) 30-39.

[2] M. Metsoviti, K. Paraskevaidi, A. Koutinas, A.-P. Zeng, S. Papanikolaou, Process Biochem. 47 (2012) 1872-1882.

[3] S. Papanikolaou, S. Fakas, M. Fick, I. Chevalot, M. Galiotou-Panayotou, M. Komaitis, I. Marc, G. Aggelis, Biomass and Bioenergy 32 (2008) 60-71.

[4] Z. Chi, D. Pyle, Z. Wen, C. Frear, S. Chen, Process Biochem. 42 (2007) 1537-1545.

[5] Y. Zheng, X. Chen, Y. Shen, Chem. Rev. 108 (2008) 5253-5277.

[6] K. Petrov, P. Petrova, Appl. Microbiol. Biotechnol. 84 (2009) 659-665.

[7] D. Rittmann, S.N. Lindner, V.F. Wendisch, Appl. Environ. Microbiol. 74 (2008) 6216-6222.

[8] M. Khamduang, K. Packdibamrung, J. Chutmanop, Y. Chisti, P. Srinophakun, J. Ind. Microbiol. Biotechnol. 36 (2009) 1267-1274.

[9] H. Habe, T. Fukuoka, D. Kitamoto, K. Sakaki, Appl. Microbiol. Biotechnol. 84 (2009) 445-452.

[10] S.J. Sarma, S.K. Brar, E.B. Sydney, Y. Le Bihan, G. Buelna, C.R. Soccol, Int. J. Hydrogen Energy 37 (2012) 6473-6490.
[11] M.J.A. Stevens, S. Vollenweider, P. Mertes, C. Lacroix, Biochem. Eng. J. 79 (2013) 239-245.

[12] S. Abad, X. Turon, Biotechnol. Adv. 30 (2012) 733-741.

[13] B.T. Maru, A.A.M. Bielen, M. Constantí, F. Medina, S.W.M. Kengen, Int. J. Hydrogen Energy 38 (2013) 5563-5572.

[14] H. Habe, T. Fukuoka, D. Kitamoto, K. Sakaki, J. Oleo Sci. 58 (2009) 595-600.

[15] Y. Huang, Z. Li, K. Shimizu, Q. Ye, Bioresour. Technol. 103 (2012) 351-359.

[16] T. Chookaew, S. O-Thong, P. Prasertsan, Int. J. Hydrogen Energy 37 (2012) 13314-13322.

[17] V.E.T. Maervoet, M. De Mey, J. Beauprez, S. De Maeseneire, W.K. Soetaert, Org. Process Res. Dev. 15 (2011) 189-202.

[18] R.K. Saxena, P. Anand, S. Saran, J. Isar, Biotechnol. Adv. 27 (2009) 895-913.

[19] D.M. Rossi, J.B. da Costa, E.A. de Souza, M.C.R. Peralba, M.A.Z. Ayub, Renew Energy 39 (2012) 223-227.

[20] D.M. Rossi, E.A. de Souza, S.H. Flôres, M.A.Z. Ayub, Renew. Energy 55 (2013) 404-409.

[21] G. Kaur, A.K. Srivastava, S. Chand, Biochem. Eng. J. 64 (2012) 106-118.

[22] G. Chotani, T. Dodge, A. Hsu, M. Kumar, R. LaDuca, D. Trimbur, W. Weyler, K. Sanford, Biochim. Biophys. Acta 1543 (2000) 434-455.

[23] T. Homann, C. Tag, H. Biebl, W.-D. Deckwer, B. Schink, Appl. Microbiol. Biotechnol. 33 (1990) 121-126.

[24] H. Biebl, K. Menzel, A.-P. Zeng, W.-D. Deckwer, Appl. Microbiol. Biotechnol. 52 (1999) 289-297.

[25] G. Yang, J. Tian, J. Li, Appl. Microbiol. Biotechnol. 73 (2007) 1017-1024.

[26] M.-Y. Seo, J.-W. Seo, S.-Y. Heo, J.-O. Baek, D. Rairakhwada, B.-R. Oh, P-S. Seo, M.H. Choi, C.H. Kim, Appl. Microbiol. Biotechnol. 84 (2009) 527-534.

[27] J.-G. Zhu, S. Li, X.-J. Ji, H. Huang, N. Hu, World J. Microbiol. Biotechnol. 25 (2009) 1217-1223.

[28] B.-R. Oh, W.-K. Hong, S.-Y.Heo, L.H. Luo, A. Kondo, J.-W. Seo, C.H. Kim, Bioresour Technol. 130 (2013) 719-724.

[29] S. Sattayasamitsathit, P. Prasertsan, P. Methacanon, Process Biochem. 46 (2011) 608-614.

[30] Y.-Z. Xu, N.-N. Guo, Z.-M. Zheng, X.-J. Ou, H.-J. Liu, D.-H. Liu, Biotechnol. Bioeng. 104 (2009) 965-972.

[31] M. Durgapal, V. Kumar, T.H. Yang, H.J. Lee, D. Seung, S. Park, Bioresour. Technol 159 (2014) 223-231.

[32] G. Zhang, B. Ma, X. Xu, C. Li, L. Wang, Biochem. Eng. J. 37 (2007) 256-260.

[33] H. Biebl, A.-P. Zeng, K. Menzel, W.-D. Deckwer, Appl. Microbiol. Biotechnol. 50 (1998) 24-29.

[34] M. González-Pajuelo, I. Meynial-Salles, F. Mendes, P. Soucaille, I. Vasconcelos Appl. Environ. Microbiol. 72 (2006) 96-101.

[35] X.-J. Ji, H. Huang, J.-G. Zhu, N. Hu, S. Li, Appl. Biochem. Biotechnol. 159 (2009) 605-613.

[36] C. Seifert, S. Bowien, G. Gottschalk, R. Daniel, Eur. J. Biochem. 268 (2001) 2369-2378.

[37] C. Hongwen, F. Baishan, H. Zongding, Biochem. Eng. J. 25 (2005) 47-53.

[38] Y.Q. Sun, W.T. Qi, H. Teng, Z.L. Xiu, A.P. Zeng, Biochem. Eng. J. 38 (2008) $22-32$.

[39] K. Ahrens, K. Menzel, A.-P. Zeng, W.-D. Deckwer, Biotechnol. Bioeng. 59 (1998) $544-552$. 